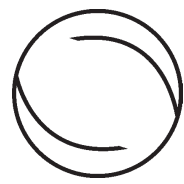

\title{
On the Explanatory Power of Generalized Darwinism: Missing Items on the Research Agenda
}

Organization Studies 34(7) 993-999

(c) The Author(s) 2013

Reprints and permissions: sagepub.co.uk/journalsPermissions.nav DOI: $|0.1| 77 / 01708406|348586|$

www.egosnet.org/os

@AGE

\section{Markus Scholz}

FHWien, University of Applied Sciences of WKW, Vienna, Austria

\section{Thomas A. C. Reydon}

Leibniz Universität Hannover, Germany

\begin{abstract}
In a recent article in this journal, Geoffrey Hodgson points out that the notion of 'evolution' is widely used in organization science without authors being sufficiently clear on what exactly they mean by this term. In his article, Hodgson cleans up the terminological and conceptual confusion on evolution in organization science and positions so-called 'generalized Darwinism' as the only well-elaborated evolutionary framework available in social science. We doubt, however, whether in its present form generalized Darwinism itself constitutes a viable approach. In this article we argue that Hodgson and collaborators so far have failed to show that generalized Darwinism is actually capable of serving as a basis for the construction of evolutionary explanations of social and organizational phenomena. We suggest a few items that should be put on generalized Darwinism's research agenda in order to develop it towards a viable option.
\end{abstract}

\section{Keywords}

evolution, generalized Darwinism, organizational populations

\section{Introduction}

In a recent article in this journal, Hodgson (2013) points out - correctly, we believe - that the notion of 'evolution' is widely used in organization science without authors being sufficiently clear on what exactly they mean by this term. As Hodgson writes, "Terms such as "evolution" or "coevolution" are often used with gravitas, as if they signify something important; but without further specification they actually mean very little. One is left asking what kind of evolutionary theory or meta-theoretical framework is intended' (Hodgson, 2013, p. 974). Accordingly, Hodgson devotes much of his article to cleaning up the terminological and conceptual confusion on evolution, and especially Darwinian evolution, in organization science (Hodgson, 2013, pp. 973-974). In 
addition, Hodgson aims to 'indicate how the principles of generalized Darwinism can be useful as an overall framework for helping to understand organizational evolution' (Hodgson, 2013, p. 974).

We very much appreciate this timely attempt to clean up conceptual confusions relating to the term 'evolution' in organization science. The use of evolutionary terminology in organization science, as well as in the social sciences more generally, is indeed excessively booming and in many cases it remains unclear in what meaning terms are used. ${ }^{1}$ However, we are critical about the more innovative and constructive part of Hodgson's work, a view he calls 'generalized Darwinism'. This is a general conceptual framework that is based on the core principles of Darwinism and can be used as a basis for explaining change processes in complex population systems both within and outside the biological realm. ${ }^{2}$ Hodgson presents generalized Darwinism as a framework that is true to the original principles of Darwinism, as well as to more recent developments in biology, the philosophy of biology, and evolutionary economics. He positions generalized Darwinism as the only well-elaborated option available in the spectrum of evolutionarily motivated research programs in the social sciences, other usages of evolutionary concepts in social science being profoundly underdeveloped. As Hodgson writes: 'If generalized Darwinism is rejected, then what is intended by "evolution" or "coevolution" must be clearly specified. In fact, no viable alternative general conceptual framework for addressing evolution in complex population systems exists' (Hodgson, 2013, p. 974).

While it may well be the case that other frameworks in the social sciences that use evolutionary notions are even less viable than generalized Darwinism, we doubt whether at this point generalized Darwinism itself constitutes a viable option. In what follows, we highlight some items that proponents of generalized Darwinism should place on their research agenda in order to establish that their approach actually has a role to play in the investigation of social and organizational phenomena.

\section{Challenges for Generalized Darwinism}

At present, three main lines of work can be distinguished in evolutionary thinking about economic and organizational phenomena: the Neo-Schumpeterian school (e.g. Nelson, 1995, 2006, 2007; Nelson \& Winter, 1982, 2002), the line of work based on Witt's so-called 'continuity hypothesis' (e.g. Cordes, 2006, 2007; Witt, 2003, 2004, 2006, 2008) and generalized Darwinism. One important aspect on which these three approaches show considerable differences is the way they conceive of the relation of their own theoretical framework to biological evolutionary theory. Of these three approaches, only generalized Darwinism rests on the assumption that evolutionary processes of the same sort as are found in the biological realm actually occur in the social world.

For example, Nelson and Winter have long taken a view of evolutionary economics and evolutionary social science as mainly involving analogies with biology that are useful for heuristic purposes but should not be stretched beyond heuristic contexts. For Nelson and Winter, we may talk about social phenomena using evolutionary terminology but should not take this to indicate that evolution actually occurs in the social domain. Proponents of the continuity hypothesis view the relation between biological evolution and socio-economic evolution in a different manner. On this view, an evolutionary approach in social science is warranted because evolution in the socioeconomic realm (as a cultural phenomenon) emerged from the biological evolution of humankind and in this sense is continuous with it, although socio-economic evolution has developed into a different sort of process from biological evolution. Therefore, it should be possible to draw lessons from biological evolution that might help us understand the processes and products of socio-economic evolution, while keeping in mind that the two sorts of evolutionary processes are quite 
distinct kinds of processes that do not fit into a common description. Hodgson and collaborators strongly oppose both these views. Against the neo-Schumpeterian view they propose that evolutionary social science should go beyond the drawing of mere analogies toward the development of a general evolutionary theory from which specific explanations can be derived for specific phenomena in specific domain. Against the continuity hypothesis they hold a view of biological and socio-economic evolution as - admittedly distinct - processes that, notwithstanding their many differences, still can be understood within the same general theoretical framework as special cases of the same general process. Hodgson's project, then, is to elaborate a general theory of evolutionary processes - in the biological realm, in the social realm and elsewhere - based on the core principles and concepts of Darwinism.

Similarly to evolutionary biology, generalized Darwinism seeks to explain the evolution of populations that consist of similar but non-identical entities that face locally scarce resources and problems of survival, and have the ability to reproduce. The entities in question can be biological entities (as generalized Darwinism is supposed to cover all instances of evolutionary processes, wherever these occur), but also organizations and other kinds of entities. Hodgson and collaborators emphasize in their publications that such evolving populations include populations of business firms (Hodgson, 2013, p. 978), such that generalized Darwinism can serve as the foundation of business studies from an evolutionary perspective. The project is supported by an ontological claim. It 'relies on the claim of common abstract features in both the social and the biological world' (Hodgson, 2013, p. 978; also Aldrich et al., 2008, p. 579), that is, the claim that there is 'a degree of ontological communality, at a high level of abstraction and not at the level of detail' (Hodgson, 2013, p. 978) between biological and social evolution. This ontological commonality pertains to the three core processes of Darwinian evolution - replication, selection and variation (Hodgson, 2013, p. 978) - as well as the basic kinds of entities participating in evolutionary processes - replicators and interactors (Hodgson, 2013, pp. 976-978). Wherever these processes and entities are found, Hodgson and collaborators claim, Darwinian evolution inevitably occurs.

A first point of criticism we want to put forward is that proponents of generalized Darwinism are insufficiently clear when it comes to naming the actual explananda that are in focus. It is not spelled out in any detail what kind of phenomena generalized Darwinism aims to explain, other than that it seeks to explain the evolution of populations of, in the present case, organizations and business firms. Of course, Hodgson (in his various publications on the topic) provides clues by stating that generalized Darwinism's purpose is to explain change processes in industries (Aldrich et al., 2008, p. 583; Hodgson, 2013, p. 978; Hodgson \& Knudsen, 2006a, pp. 4-5; Hodgson \& Knudsen, 2010, pp. 34, 40). But that is more or less all that is being said. The question then remains what kind of change phenomena exactly generalized Darwinism aims to explain. There are indeed many possibilities. For instance, organizational ecology, a well-known research programme in organization science that many authors conceive of as being built on Darwinian foundations (and that Hodgson refers to as a seminal line of work in the Darwinian spirit in organization science) addresses at least four comparatively well-articulated explananda, namely: organizational diversity; distributions of organizations across different social and economic environments; limitations imposed on possible organizational forms by their environments; and rates of organizational establishment, change and termination (see Hannan \& Freeman, 1977, 1984; Reydon \& Scholz, 2009, p. 415).

Interestingly, not all explananda of organizational ecology seem to be in focus in Hodgson's approach. Only the latter of the four explananda mentioned above concerns change processes themselves, while the other three concern the product of such processes and their boundary conditions. One thus may wonder whether generalized Darwinism is intentionally conceived as 
narrower with respect to its explanatory scope than other evolution-based lines of work in social and organization science. If this narrower scope is intended, then why is this? The two principal explananda of biological evolutionary theory are the extant diversity of organisms and their adaptedness to life in their particular environments (e.g. Charlesworth \& Charlesworth, 2003; Van Dijk \& Reydon, 2010, p. 658). So it can be expected that these two explananda - or their counterparts in the social/organizational domain - should also be in focus in generalized Darwinism. That is, it seems reasonable to expect that generalized Darwinism should be able to explain both evolutionary processes in the social domain and aspects of their products (i.e. diversity and adaptedness). In the case that these explananda are in focus and the explanatory scope of generalized Darwinism is not intended to be narrower than that of other evolutionary lines of investigation, the next step would be to establish that generalized Darwinism has the resources to explain the phenomena it is intended to explain. Elsewhere (Reydon \& Scholz, 2009; Scholz \& Reydon 2008, 2010) we have criticized organizational ecology for not being able to provide proper evolutionary explanations of its explananda and we believe that our basic criticism of organizational ecology holds against generalized Darwinism too. (We will turn to this issue in the next section.) But in the case of generalized Darwinism the additional problem occurs that in the absence of clearly circumscribed explananda it becomes difficult to assess whether generalized Darwinism will be able to achieve its explanatory aims.

It is possible, of course, that at this point we expect too much from generalized Darwinism. Perhaps generalized Darwinism is still in a very early stage of its development and more detailed accounts will be forthcoming. Moreover, Hodgson and collaborators repeatedly state that they do not intend to develop a detailed evolutionary theory for the social/organizational domain, but rather a general, overarching framework based on the principles of Darwinian evolution that itself is nonexplanatory but within which explanations for concrete domains can be formulated by filling in the relevant details (Aldrich et al., 2008, pp. 580, 585; Hodgson, 2002, p. 273; Hodgson, 2013). But even if we grant all this, there remains (at least) one severe problem for generalized Darwinism that its proponents should place on their research agenda. This problem has to do with a central aspect of the ontology of evolution, namely, the nature of evolving populations.

At the heart of Hodgson's project lies the assumption that populations of organizations can be studied by using general Darwinian principles (Aldrich et al., 2008, p. 582; Hodgson, 2013, p. 978; Hodgson \& Knudsen, 2006, p. 6, 16; Hodgson \& Knudsen, 2010, p. 34). These populations consist of organizations of a certain type, where organization types are defined by particular key aspects in which their members resemble one another. As Hodgson (2013, p. 978) specifies, the populations of organizations, within which evolutionary processes occur, are defined as 'sets of individually different and demarcated entities that interact with the environment and each other'. In the case of populations of organizations and firms, organizational types are defined by distinctive capacities organizations have to deal with scarcity of resources and competition against various other entities. Such capacities, proponents of generalized Darwinism claim, are inherited.

The problem, now, is this. Contrary to the definition of organizational populations as sets of organizations sharing a number of traits, in evolutionary biology populations are conceived of as reproductive communities, i.e. systems of reproductively interconnected organisms. ${ }^{3}$ Biological populations are not defined as sets of organisms with a number of traits in common. From the perspective of generalized Darwinism, any member of a particular organizational population must exhibit the particular traits that define the population. But then variation within organizational populations - one of the driving factors in evolution, as Hodgson (2013, p. 978) rightly states - is quite limited: the members of an organizational population cannot vary too much with respect to the population's defining traits. Thus, novelties can only occur to a limited degree within an 
organizational population: any novelty regarding the cluster of traits that defines the population can easily entail that the organization bearing the new trait no longer is a member of the population. Thus, minor innovations can occur, but no really new kinds of organization can come into being as a consequence of evolution within an existing population. Innovation can occur in non-evolutionary ways, of course. But such innovations cannot be explained by invoking evolution.

As a consequence of its definition of organizational populations in terms of shared key traits of their member organizations the explanatory force of generalized Darwinism seems severely limited. Our challenge to proponents of generalized Darwinism thus is to formulate a definition of organizational populations that is compatible with the Darwinian view of evolution and to examine whether a framework results that can explain organizational change in the same way as biological Darwinism explains organismal change.

\section{Conclusion}

On the one hand the possibility that evolutionary processes in a strict sense could also occur in in realms outside biology, such as the organizational domain, should not be rejected without further investigation. On the other hand, however, it should not be simply assumed that such processes can and actually $d o$ occur outside the living world. Evolution in the strict sense might or might not be a process that is confined to the living world - ultimately this is an empirical issue. But even if evolutionary processes do occur outside the living world, it cannot be assumed without further argumentation that it will be possible to formulate a general description of all the various evolutionary processes, of the sort envisaged by proponents of generalized Darwinism, that will be able to do actual heuristic, explanatory, etc. work in investigative contexts.

In our view, attempts at formulating theories of evolution that go beyond the biological domain should be welcomed in principle. After all, showing that the same basic process occurs in widely divergent realms and that the same theory can be used to explain different kinds of phenomena in divergent domains is an important aspect of progress in science. And in case the existence of deep commonalities between biological and organizational evolution is established, it could be possible to use results from evolutionary biology (mathematical models developed for evolving populations of living organisms, for instance) to study phenomena in the organizational domain. However, treating a variety of phenomena that are dissimilar under an overarching framework may also lead investigative efforts astray by propagating a misconceived view of (at least some of) the phenomena under consideration. Thus, a good measure of caution is called for not to invoke Darwinian evolutionary theory too quickly to describe and explain phenomena outside the original scope of the theory.

So the question arises on whose side the burden of proof is to be placed: with those advocating the generalization of Darwinism or with those, like us, who suggest caution? We think it lies with those who make the positive claim that change in the organizational domain is Darwinian in any proper sense of the term. Any attempt at establishing a generalized evolutionary theory we believe should include a demonstration - by means of thoroughly elaborated examples - that the processes in the various domains which the theory is supposed to cover are sufficiently similar in order to be considered local instantiations of the same general process. We have pointed to some of the issues that have to be clarified before generalized Darwinism could serve as the basis for a research agenda in organization science, as Hodgson intends it to be. Elaborating generalized Darwinism further with respect to these issues in our view constitutes a necessary - but probably not yet sufficient - requirement for the approach to be able to count as a serious option for researchers in organization science and the social sciences more broadly. 


\section{Funding}

This research received no specific grant from any funding agency in the public, commercial or not-for-profit sectors.

\section{Notes}

1. As a recent bibliometic study shows, the mass of evolutionarily inspired literature in economic fields of research has shown a sharp increase in the past 20-25 years (Silva \& Teixeira, 2009).

2. Hodgson and collaborators elaborated generalized Darwinism in a number of publications, including Aldrich et al. (2008), Hodgson (2002, 2003) and Hodgson and Knudsen (2004, 2006a, 2006b, 2008, 2010).

3. We have developed this argument with respect to the specific research programme of organizational ecology elsewhere (Reydon \& Scholz, 2009; Scholz \& Reydon, 2008, 2010). The problem that generalized Darwinism faces is essentially the same as that faced by organizational ecology. As we have spelled out the issue in other publications, here we give only a brief summary.

\section{References}

Aldrich, H. E., Hodgson, G. M., Hull, D. L., Knudsen, T., Mokyr, J., \& Vanberg, V. J. (2008). In defence of generalized Darwinism. Journal of Evolutionary Economics, 18, 577-596.

Charlesworth, B., \& Charlesworth, D. (2003). Evolution: A very short introduction. New York: Oxford University Press.

Cordes, C. (2006). Darwinism in economics: From analogy to continuity. Journal of Evolutionary Economics, $16,529-541$.

Cordes, C. (2007). Turning economics into an evolutionary science: Veblen, the selection metaphor, and analogical thinking. Journal of Economic Issues, 41, 135-154.

Hannan, M. T., \& Freeman, J. (1977). The population ecology of organizations. American Journal of Sociology, 82, 929-964.

Hannan, M. T., \& Freeman, J. (1984). Structural inertia and organizational change. American Sociological Review, 49, 149-164.

Hodgson, G. M. (2002). Darwinism in economics: From analogy to ontology. Journal of Evolutionary Economics, 12, 259-281.

Hodgson, G. M. (2003). The mystery of the routine: The Darwinian destiny of An Evolutionary Theory of Economic Change. Revue Économique, 54, 355-384.

Hodgson, G. M. (2013). Understanding organizational evolution: Toward a research agenda using generalized Darwinism. Organization Studies, 34, 973-992.

Hodgson, G. M., \& Knudsen, T. (2004). The firm as an interactor: Firms as vehicles for habits and routines. Journal of Evolutionary Economics, 14, 281-307.

Hodgson, G. M., \& Knudsen, T. (2006a). Why we need a generalized Darwinism and why a generalized Darwinism is not enough. Journal of Economic Behavior \& Organization, 61, 1-19.

Hodgson, G. M., \& Knudsen, T. (2006b). The nature and units of social selection. Journal of Evolutionary Economics, 16, 477-489.

Hodgson, G. M., \& Knudsen, T. (2008). In search of general evolutionary principles: Why Darwinism is too important to be left to the biologists. Journal of Bioeconomics, 10, 51-69.

Hodgson, G. M., \& Knudsen, T. (2010). Darwin's conjecture: The search for general principles of social and economic evolution. Chicago: University of Chicago Press.

Nelson, R. R. (1995). Recent evolutionary theorizing about economic change. Journal of Economic Literature, $33,48-90$.

Nelson, R. R. (2006). Evolutionary social science and Universal Darwinism. Journal of Evolutionary Economics, 16, 491-510.

Nelson, R. R. (2007). Universal Darwinism and evolutionary social science. Biology \& Philosophy, 22, 73-94. 
Nelson, R. R., \& Winter, S. G. (1982). An evolutionary theory of economic change. Cambridge, MA: Harvard University Press.

Nelson, R. R., \& Winter, S. G. (2002). Evolutionary theorizing in economics. Journal of Economic Perspectives, 16, 23-46.

Reydon, T. A. C., \& Scholz, M. (2009). Why organizational ecology is not a Darwinian research program. Philosophy of the Social Sciences, 39, 408-439.

Scholz, M., \& Reydon, T. A. C. (2008). The population ecology programme in organisation studies: Problems caused by unwarranted theory transfer. Philosophy of Management, 6, 57-69.

Scholz, M., \& Reydon, T. A. C. (2010). Organizational ecology: No Darwinian evolution after all. A rejoinder to Lemos. Philosophy of the Social Sciences, 40, 504-512.

Silva, S. T., \& Teixeira, A. C. (2009). On the divergence of evolutionary research paths in the past 50 years: A comprehensive bibliometric account. Journal of Evolutionary Economics, 19, 605-642.

Van Dijk, E. M., \& Reydon, T. A. C. (2010). A conceptual analysis of evolutionary theory for teacher education. Science \& Education, 19, 655-677.

Witt, U. (2003): The evolving economy: Essays on the evolutionary approach in economics. Cheltenham, UK: Edward Elgar.

Witt, U. (2004). On the proper interpretation of 'evolution' in economics and its implications for production theory. Journal of Economic Methodology, 11, 125-146.

Witt, U. (2006). Evolutionary concepts in economics and biology. Journal of Evolutionary Economics, 16, 473-476.

Witt, U. (2008). What is specific about evolutionary economics? Journal of Evolutionary Economics, 18, $547-575$.

\section{Author biographies}

Markus Scholz holds the endowed professorship in Corporate Governance \& Business Ethics at the FHWien, University of Applied Sciences of WKW, Vienna. In addition he is a research associate at the Centre for Philosophy of Natural and Social Science (CPNSS) at the London School and Economics and Political Science (LSE) and Zicklin Fellow at the Carol and Lawrence Zicklin Center for Business Ethics Research at the Wharton School/University of Pennsylvania. Previously he was a postdoctoral research fellow at the Centre for Philosophy and ethics of Science, Leibniz Universität Hannover and led the Philosophy and Ethics of Economics Research - Group (PEER). His principal area of research is business ethics, but he also has strong research interests in the philosophies of management and economics.

Thomas A. C. Reydon is Junior Professor of Philosophy of Biology at the Institute of Philosophy, Leibniz Universität Hannover. He received Master's degrees (physics and philosophy of science) and a Doctorate (philosophy of biology) from Leiden University. His principal area of research is philosophy of biology, but he also has research interests in the philosophies of other domains of science, in general philosophy of science and in metaphilosophy. He is associate editor for philosophy of biology of the journal Acta Biotheoretica and joint Editor-in-Chief of the Springer book series History, Philosophy and Theory of the Life Sciences. 